\title{
Erratum to: Etiology and Morphogenesis of Congenital Heart Disease
}

Toshio Nakanishi, Roger R. Markwald, H. Scott Baldwin, Bradley B. Keller, Deepak Srivastava, and Hiroyuki Yamagishi

\section{Erratum to: \\ T. Nakanishi et al. (eds.), Etiology and Morphogenesis of Congenital Heart Disease, https://doi.org/10.1007/978-4-431-54628-3}

The original online version of this book was inadvertently published with incorrect affiliation details of the editors. This has now been amended with the correct affiliation details. 